\title{
Apnea-hypopnea index use among intensive care patients: a case series
}

Bülent Gücyetmez ${ }^{1 *}$ and Hakan Korkut Atalan²

\begin{abstract}
Introduction: ApneaLink ${ }^{\mathrm{TM}}$ (RESMED-Munich, Germany) is a simple and inexpensive device that determines the apnea-hypopnea index. The sensitivity and specificity of the apnea-hypopnea index are 100 and $87.5 \%$, respectively. Our hypothesis can be used to create a treatment plan using the apnea-hypopnea index for intensive care unit patients.

Case presentation: This treatment plan has been created by determining the apnea-hypopnea index of eight Caucasian patients with a variety of diagnoses. Case 1 is that of a 70-year-old man diagnosed with rectum cancer and scheduled for elective surgery. Case 2 is that of a 65-year-old man diagnosed with rectum cancer and scheduled for elective surgery. Case 3 is that of a 78-year-old woman diagnosed with chronic obstructive pulmonary disease-pneumonia. Case 4 is that of a 26-year-old man diagnosed with head trauma. Case 5 is that of an 80-year-old man diagnosed with cerebrovascular disease. Case 6 is that of a 79-year-old man diagnosed with cerebrovascular disease. Case 7 is that of an 8-year-old girl diagnosed with ventricular septal defect-epidural hemorragia. Case 8 is that of a 42 -year-old man diagnosed with subarachnoid hemorrage.

Conclusions: The apnea-hypopnea index can be informative regarding prognosis and outcomes, and helps to take precautions and develop new treatment strategies among critical patients in intensive care. The integration of developments in sleep medicine to intensive care unit practices means that we can be more informed about critical patients.
\end{abstract}

Keywords: Apnea-hypopnea index, AHI, Brain death

\section{Introduction}

ApneaLink $^{\mathrm{mat}}$ (RESMED-Munich, Germany) is a simple and inexpensive device that determines the apnea-hypopnea index (AHI). The AHI, hypopnea index (HI), and oxygen desaturation index (ODI) are calculated using breath flow, peripheral oxygen saturation, and heart rate (HR) during night's sleep. The sensitivity and specificity of AHI are 100 and $87.5 \%$, respectively [1]. With these features ApneaLink $^{\text {tim }}$ can contribute to the diagnosis and treatment of intensive care patients. Therefore, we present the following eight Caucasian patients from our intensive care unit (ICU) where diagnosis and treatment plan decisions were made using the AHI.

\footnotetext{
* Correspondence: drbulentgucyetmez@yahoo.com

'Intensive Care Unit, International Hospital, Istanbul Cad No: 82 Yesilkoy, 34149 Istanbul, Turkey

Full list of author information is available at the end of the article
}

\section{Case presentation}

Case 1 involved a 70-year-old man with a medical history of chronic obstructive pulmonary disease (COPD), hypertension (HT), and rectal cancer. He had a body mass index (BMI) of $28.3 \mathrm{~kg} / \mathrm{m}^{2}$ and a score of 2 on Epworth sleepiness scale (ESS) and was scheduled for an open abdominal surgery. One day prior to the surgery, he performed an apnea test (via ApneaLink ${ }^{\mathrm{Tx}}$ ) between 00:00 and 06:00 am which yielded the following results: AHI: 17/hr, AI: 3/hr, HI: 14/hr; ODI: 3/hr, minimum $\mathrm{SpO} 2$ (min. SpO2) 79\%, and maximum HR (max. HR): 124/min. A decision was made for postoperative ICU follow-up of the patient.

Following the three-hour long surgery, the intubated patient was admitted to the ICU, where he was extubated four hours later and given $\mathrm{O}_{2}$ mask support (5L/ $\mathrm{min})$. The results of an apnea test conducted on the operation day between 00:00 and 06:00 am were as follows: AHI: $21 / \mathrm{hr}$, AI: 4/hr, HI: 17/hr, ODI: $1 / \mathrm{hr}, \min . \mathrm{SpO}_{2}$ : $84 \%$, and max. HR: $131 / \mathrm{min}$. It was decided that he 
should be scheduled for postoperative noninvasive mechanical ventilation (NIMV) support (Table 1).

Case 2 involved a 65-year-old man with no known medical history and a diagnosis of rectal cancer. He had a BMI of $20.3 \mathrm{~kg} / \mathrm{m}^{2}$, an ESS score of 2, and was scheduled for a laparoscopic abdominal surgery. One day prior to the surgery, he performed an apnea test via ApneaLink ${ }^{\mathrm{Tw}}$ between 00:00 and 06:00 am, which yielded the following results: AHI: 22/hr, AI: 0/hr, HI: 22/hr; ODI: 3/hr, min. SpO2 86\%, and max. HR: 108/min. A decision was made for postoperative ICU follow-up of the patient.

Following the two-hour long surgery, the intubated patient was admitted to the ICU, where he was extubated at the second hour and given $\mathrm{O}_{2}$ mask support $(5 \mathrm{~L} / \mathrm{min})$. The results of the apnea test conducted on the operation day between 00:00 and 06:00 am were as follows: AHI: 38/hr, AI: 0/hr, HI: 38/hr, ODI: $1 /$ hr, min. $\mathrm{SpO}_{2}: 81 \%$, and max. HR: $101 / \mathrm{min}$. It was decided that he should be scheduled for postoperative non-invasive mechanical ventilation (NIMV) support (Table 1).

Case 3 involved a 78-year-old woman with a medical history of COPD, HT, and diabetes mellitus (DM). Her BMI score was $25.2 \mathrm{~kg} / \mathrm{m}^{2}$. She had presented to the emergency department with hypoxia, hypercapnia, tachypnea, and dyspnea, and was admitted to the ICU with a diagnosis of pneumonia. She was followed-up on in the ICU for five days, during the first two of which she was given NIMV support intermittently during the day and continuously at night. She received nasal $\mathrm{O}_{2}$ support for the following three days, and on day four she performed an apnea test between 00:00 and 06:00 am under an $\mathrm{O}_{2}$ mask $(5 \mathrm{~L} / \mathrm{min})$, which yielded the following results: $\mathrm{AHI}$ : 18/hr, AI: 8/hr, HI: 10/hr, ODI: 5/hr, min. $\mathrm{SpO}_{2} 72 \%$, and max. HR 102/min. It was decided that she should be scheduled to be discharged on bilevel positive airway pressure (BIPAP) support (Table 1).

Case 4 involved a 26-year-old man with no known medical history and a BMI of $19.5 \mathrm{~kg} / \mathrm{m}^{2}$. He was transferred to the ICU unconsciously, with a Glasgow Coma Score (GCS) score of 6 and tracheostomy due to head assault-related trauma. He stayed in the ICU for 26 days and was separated from mechanical ventilation support after 6 days. Twelve days after admission, he performed an apnea test between 00:00 and 06:00 am in the room air, which yielded the following results: AHI: 2/hr, AI: 2/ hr, HI: 0/hr, ODI: 0/hr, min. $\mathrm{SpO}_{2} 95 \%$, and max. HR: $109 / \mathrm{min}$. It was decided he should be scheduled to be discharged as tracheostomized, and with spontaneous respiration under nurse supervision (Table 1).

Case 5 involved an 80-year-old man with a diagnosis of HT and DM. He had a BMI of $27.7 \mathrm{~kg} / \mathrm{m}^{2}$ and presented to the emergency department with a high sleep tendency and plegia on the left side. A right thalamic and cerebellar infarction was detected in his cranial diffusion magnetic resonance imaging (MRI) scan. He was admitted to the ICU with GCS score of 4 . He was followed-up on in the ICU for 38 days and tracheostomized on day 21. The results of the apnea test conducted on day 26 between 00:00 and 06:00 am with the tracheostomy mask $\left(5 \mathrm{~L} / \mathrm{min} \mathrm{O}_{2}\right)$ were as follows: AHI 18/hr, AI: 6/hr, HI: 12/hr, ODI: 3/hr, min. $\mathrm{SpO}_{2}: 89 \%$, and max HR: $83 / \mathrm{min}$. It was decided he should be

Table 1 Clinical features, apnea-hypopnea index, and decisions taken for the first six cases

\begin{tabular}{|c|c|c|c|c|c|c|c|c|c|c|}
\hline & Age & Gender & Diagnose & BMI $\left(k g / m^{2}\right)$ & $\mathrm{AHI} / \mathrm{h}$ & $\mathrm{Al} / \mathrm{h}$ & ODI/h & $\mathrm{SpO}_{2}(\%)(\min )$ & $\begin{array}{l}\text { HR/min } \\
\text { (max.) }\end{array}$ & Decision \\
\hline \multirow[t]{2}{*}{ Case 1} & \multirow[t]{2}{*}{70} & \multirow[t]{2}{*}{ Male } & \multirow{2}{*}{$\begin{array}{c}\text { Rectum Cancer } \\
\text { (open abdominal surgery) }\end{array}$} & \multirow[t]{2}{*}{28.3} & Preop.; 17 & 3 & 3 & 79 & 124 & Postop. ICU admission \\
\hline & & & & & Postop.; 21 & 4 & 1 & 84 & 131 & Postop. NIMV \\
\hline \multirow[t]{2}{*}{ Case 2} & \multirow[t]{2}{*}{65} & \multirow[t]{2}{*}{ Male } & \multirow{2}{*}{$\begin{array}{c}\text { Rectum Cancer (Laparoscopic } \\
\text { abdominal surgery) }\end{array}$} & \multirow[t]{2}{*}{20.3} & Preop:; 22 & 0 & 3 & 86 & 108 & Postop. ICU admission \\
\hline & & & & & Postop.; 38 & 0 & 1 & 81 & 101 & Postop. NIMV \\
\hline Case 3 & 78 & Female & COPD & 25.2 & 18 & 8 & 5 & 72 & 102 & Discharge on BIPAP use \\
\hline Case 4 & 26 & Male & $\begin{array}{c}\text { Head Trauma } \\
\text { (Tracheostomized patient) }\end{array}$ & 19.5 & 2 & 2 & 0 & 95 & 109 & $\begin{array}{l}\text { Discharge on spontaneous } \\
\text { respiration }\end{array}$ \\
\hline Case 5 & 80 & Male & CVD (Tracheostomized patient) & 27.7 & 18 & 6 & 3 & 89 & 83 & $\begin{array}{l}\text { Discharge on home } \\
\text { ventilator use }\end{array}$ \\
\hline \multirow[t]{2}{*}{ Case 6} & 79 & Male & CVD (Tracheostomized patient) & 20.8 & 34 & 3 & 7 & 79 & 97 & $\begin{array}{l}\text { Discharge on home } \\
\text { ventilator use }\end{array}$ \\
\hline & & & & \multicolumn{2}{|c|}{$\mathrm{PaCO}_{2}$ (Pretest) } & \multicolumn{2}{|c|}{$\begin{array}{l}\mathrm{PaCO}_{2} \\
\text { (Pretest) }\end{array}$} & \multicolumn{2}{|c|}{ Apne duration } & \\
\hline Case 7 & 8 & Female & $\begin{array}{l}\text { Ventricular septal defect } \\
\text { (Brain death) }\end{array}$ & \multicolumn{2}{|c|}{$45 \mathrm{mmHg}$} & \multicolumn{2}{|c|}{$75 \mathrm{mmHg}$} & \multicolumn{2}{|c|}{5 minutes } & $\begin{array}{l}\text { Apnea can be recorded } \\
\text { and demostrated }\end{array}$ \\
\hline Case 8 & 42 & Male & $\begin{array}{l}\text { Subarachnoid hemorrhage } \\
\text { (Brain death) }\end{array}$ & \multicolumn{2}{|c|}{$41 \mathrm{mmHg}$} & $76 \mathrm{~m}$ & $\mathrm{nmHg}$ & \multicolumn{2}{|c|}{9 minutes } & $\begin{array}{c}\text { Apnea can be recorded } \\
\text { and demostrated }\end{array}$ \\
\hline
\end{tabular}


scheduled to be discharged as tracheostomized, with home care conditions assured under home ventilator support (Table 1).

Case 6 involved a 79-year-old man with a medical history of myocardial infarction, HT, and cardiac insufficiency. He had a BMI of $20.8 \mathrm{~kg} / \mathrm{m}^{2}$ and presented to the emergency department with spasms and sudden loss of consciousness. He was admitted to the ICU after a right middle cerebral artery (MCA) infarction was detected in his cranial diffusion MRI. He was followed-up on in the ICU for 16 days and he was tracheostomized on day 11 . He performed the apnea test with the tracheostomy mask $\left(5 \mathrm{~L} / \mathrm{min}_{2}\right)$ on day 15 between $00: 00$ and 06:00 am. The results were as follows: AHI 34/hr, AI: 3/ hr, HI: $31 /$ hr, ODI: 7 hr, $\min . \mathrm{SpO}_{2}: 79 \%$, and max HR: $97 /$ min. It was decided that he should be scheduled to be discharged as tracheostomized, with home care conditions assured under home ventilator support (Table 1).

Case 7 involved an 8-year-old girl with a diagnosis of ventricular septal defect. She presented to the ICU as intubated after ventricular septal defect (VSD) closure. She was on $7.4 \mathrm{mcg} / \mathrm{kg} / \mathrm{min}$ dopamine, $8 \mathrm{mcg} / \mathrm{kg} / \mathrm{hr}$ dobutamine, and $0.08 \mathrm{mcg} / \mathrm{kg} / \mathrm{min}$ adrenalin support postoperatively. She received a $1 \mathrm{mg} / \mathrm{hr}$ midazolam infusion for 14 hours and a $0.15 \mathrm{mg} / \mathrm{kg} / \mathrm{hr}$ tramadol infusion for 23 hours. After 24 hours, her pupils were dilated and an epidural hemorrhage and shift were detected in her cranial computational tomography (CT) scan, after which the epidural hemorrhage was extracted. Despite the lack of sedative administration for the first 96 postoperative hours, she was sedated and the conditions of her pupils did not change. A reverse flow was detected in her carotid Doppler scan but no intracerebral hemorrhage was detected in her cerebral angiogram. At 98 postoperative hours, she performed the standard apnea test and her ApneaLink $^{\mathrm{Tm}}$ recordings were made simultaneously. Due to the desaturation occurring at the end of the apnea test that lasted 4 minutes and 38 seconds, continuous positive airway pressure (CPAP) treatment was applied. Her $\mathrm{PaCO}_{2}$ value increased from 45 to $75 \mathrm{mmHg}$ and the ApneaLink $^{\mathrm{Tm}}$ showed that there was no respiratory effort present. This demonstrated that the presence of apnea can be seen and recorded by ApneaLink ${ }^{\text {TI }}$ during the apnea test.

Case 8 involved a 42-year-old man with a diagnosis of hypertension who presented to the ICU unconscious and after a 20-minute resuscitation. His pupils were with fixed and dilated, his GCS score was 3, he was orally intubated, and had hypotension following a loss of consciousness and cardiac arrest. After detecting a subarachnoid hemorrhage in his cranial CT scan, he was started on anti-edema therapy and sedative medication. The cerebral angiogram performed twelve hours after admission to the ICU showed that there was no cerebral hemorrhage, and so a standard apnea test was performed with ApneaLink ${ }^{\text {Tix }}$ recording the apnea data. After nine minutes, his $\mathrm{PaCO}_{2}$ value increased from 41 to $76 \mathrm{mmhg}$ and ApneaLink ${ }^{\mathrm{max}}$ showed that there was no respiratory effort present. This demonstrated that the presence of apnea can be seen and recorded by ApneaLink $^{\text {tm }}$ during the apnea test.

All patients were Caucasian.

\section{Discussion}

The aim of this article is to emphasize and discuss the importance and benefits of determining AHI among ICU patients. Yaggi et al. and Meoli et al. define apnea as an interruption of nasal airflow for at least $10 \mathrm{sec}-$ onds, and hypopnea as a decrease in the airflow that is greater than $30 \%$ accompanied by a $4 \%$ decrease in the $\mathrm{O}_{2}$ saturation [2,3]. A polysomnography (PSG) may not always be performed in the ICU but simple, inexpensive, and easy to use devices such as ApneaLink ${ }^{\text {ti }}$ can be used to determine AHI $[4,5]$. The detection of AHI among ICU patients can be beneficial in determining the diagnosis and treatment of the following cases.

\section{AHI in elective surgery patients}

The American Society of Anesthesiologists (ASA) classification [6], age [7], type of muscle relaxant [8], smoking [9], low albumin levels [10], duration of surgery [11], type of anesthesia [6,12], and other comorbidities [9] (like COPD, coronary artery disease, and kidney failure) are associated with the development of complications. Preoperative complications are most frequently observed in abdominal surgeries [13]. In their retrospective study Gupta et al. reported that obstructive sleep apnea syndrome (OSAS) patients undergoing orthopedic surgery experience more complications during their postoperative period and have longer hospital stays [14]. Case 1 and Case 2 had high AHI during their preoperative period, independent of their BMIs. In such cases it is likely that the patient may have an obstructive sleep apnea syndrome (OSAS) diagnosis that they are not aware of. Information on preoperative AHI provides an opportunity both to review the anesthesia plan and consider postoperative intensive care follow-up. This feature of AHI may prove that it is useful in practice for the preoperative evaluation of anesthesia. Additionally, both of these cases had an increase in AHI postoperatively, particularly in favor of hypopnea. Postoperative increase in AHI may be associated with the surgical technique used and/or inadequate or excessive analgesia. In such a case, AHI may be used to question the surgical technique and the analgesic regimens. A postoperative AHI increase can lead to atelectasis and may require treatment such as postoperative NIMV support. Under such circumstances, 
AHI detection in elective surgery patients can provide significant benefits.

\section{AHI among ICU patients with COPD diagnosis}

The comorbidity of COPD and OSAS is defined as an overlap syndrome (OS) [15]. Compared to COPD, more frequent hypoxia, arrhythmia, pulmonary hypertension, and heart failure are observed in OS [16]. OSAS alone has also been shown to increase the risk of stroke and death [2]. Young et al. have emphasized that OSAS has a high prevalence and a significant amount of the cases are undiagnosed OSAS [17]. Given this fact, determining AHI among COPD patients followed-up on in the ICU is significant for estimating possible risks and mortality. Case 3 was followed-up on in the ICU with COPD and pneumonia diagnoses. It is unclear whether the patient whose infection status had regressed and clinical condition had enhanced had OSAS in addition to the COPD diagnosis. Researching OSAS by defining the patient's OS condition would help to understand the possible risks and determine the postoperative intensive care treatment plan more effectively. The patient having high AHI was diagnosed with OS and discharged with BIPAP. Therefore, determining AHI among ICU patients with COPD diagnosis should be standardized during their hospital stay.

\section{AHI among tracheostomized patients regarding the home ventilator use decision}

The incidence rate of tracheostomy among intensive care patients is $24 \%$ [18]. A tracheostomy provides advantages such as reducing dead space, increasing patient comfort, reducing airway resistance, and ease of aspiration compared to endotracheal intubation [19]. Hsu et al. reported that a tracheostomy applied before 21 days after an unsuccessful weaning reduces mortality, and emphasized that long intubation periods prior to a tracheostomy prolong the ICU stay and negatively affect the success of weaning [20]. In this study, it has been reported that ventilator need increased among tracheostomized patients who developed pneumonia, had a $\mathrm{PaO}_{2} /$ $\mathrm{FiO}_{2}$ value below 250, or were tracheostomized after 21 days. There are objective criteria in the literature on tracheostomy indication, timing, and decannulation indications [20-23]. However, we have more subjective knowledge on the timing and duration of post-tracheostomy mechanical ventilation support. The use of mechanical ventilation support when unnecessary or lack of its use when necessary are both harmful for a tracheostomized patient. Apnea detected in a tracheostomized patient may only be central apnea, and hypopnea presence means hypoventilation and atelectasis, both of which require mechanical ventilation support. Trigeminocardiac reflexrelated arrhythmia can be seen in patients who have undergone aneurysm surgery, while apnea can occur in patients diagnosed with intracerebral bleeding [24,25]. Normal AHI values on the other hand show that no mechanical ventilation support is needed. Cases 4,5 , and 6 were tracheostomized for different reasons and the decision whether to use a home ventilator was given based on their AHI. Therefore, AHI can be used as an objective criterion in determining the mechanical ventilation need for tracheostomized patients.

\section{Detection and recording of apnea during the apnea test in cases of brain death}

In case of brain death, an apnea test is an important reliable method to evaluate the medullary respiratory center's functions [26,27]. Evaluation of the cerebral blood flow is recommended when the results of the 'apnea test' are suspected. Prior to the apnea test, it is made sure the patient is normotensive, normothermic, and normocapnic $\left(\mathrm{PaCO}_{2} 35 \mathrm{mmHg}\right.$ to $\left.45 \mathrm{mmHg}\right)$, with $\mathrm{SpO}_{2}$ less than 95\% via mechanical ventilation support with $\mathrm{FiO}_{2}$ at $100 \%$ and positive end expiratory pressure (PEEP) at $5 \mathrm{cmH}_{2} \mathrm{O}$ [28]. An apnea test result is considered as positive if the $\mathrm{PaCO}_{2}$ value increases beyond $60 \mathrm{mmHg}$ or more than $20 \mathrm{mmHg}$ when the patient is separated from mechanical ventilation for 10 minutes and is given 100\% oxygen at $6 \mathrm{~L} /$ minute rate [28]. Complications such as hypoxia, arrhythmia, acidosis, and hypotension associated with being separated from mechanical ventilation can occur during the apnea test [29-31]. In case of a complication, the apnea test is performed with a T-piece or under continuous positive air pressure (CPAP) [32]. A case of cardiac arrest is recorded by showing lack of rhythm via electrocardiography (ECG). Therefore, we believe that recording apnea test positivity along with apnea in the case of a significant clinical condition such as brain death will provide significant advantages. The presence of apnea was recorded via simultaneous ApneaLink $^{\mathrm{Tm}}$ while a standard apnea test was performed on the patients in Case 7 and 8. While a recorded apnea in brain death provides more objective and significant data, it can also prevent possible complications by shortening the time waiting for apnea.

\section{Conclusions}

AHI can be informative regarding prognosis and outcomes and helps to take precautions and develop new treatment strategies among critical patients in the ICU. The integration of developments in sleep medicine to ICU practices means that we can be more informed about critical patients.

\section{Consent}

For Cases 1 to 6, written informed consent was obtained from the patients for publication of these case reports 
and any accompanying figures. A copy of the written consent is available for review by the Editor-in-Chief of this journal.

For the minor patient (Case 7), written informed consent was obtained from the patient's legal guardian(s) for publication of this case report and any accompanying images. A copy of the written consent is available for review by the Editor-in-Chief of this journal.

For Case 8, written informed consent was obtained from the patient's next of kin for publication of this case report and any accompanying images. A copy of the written consent is available for review by the Editor-inChief of this journal.

\begin{abstract}
Abbreviations
Al: Apnea Index; AHI: Apnea-hypopnea index; ASA: The American Society of Anesthesiologists; BIPAP: Bilevel Positive Airway Pressure; BMI: Body Mass Index; COPD: Chronic Obstructive Pulmonary Disease; CVD: Cerebrovascular Disease; CT: Computational Tomography; CPAP: Continuous Positive Airway Pressure; DM: Diabetes Mellitus; ESS: Epworth Sleepiness Scale; GCS: Glasgow Coma Score; HI: Hypopnea Index; HR: Heart Rate; HT: Hypertension; ICU: Intensive Care Unit; MRI: Magnetic Resonance Imaging; MCA: Middle Cerebral Artery; NIMV: Non-Invasive Mechanical Ventilation; ODI: Oxygen Desaturation Index; OSAS: Obstructive Sleep Apnea Syndrome; OS: Overlap Syndrome; SpO2: Peripheral Oxygen Saturation; PSG: Polysomnography; PEEP: Positive End Expiratory Pressure.
\end{abstract}

\section{Competing interests}

The authors declare that they have no competing interests.

\section{Authors' contributions}

BG was involved in the initial writing of the manuscript. HKA provided intellectual contributions to the content of the manuscript as well as editorial assistance. All authors have read and approved the final version of the manuscript.

\section{Acknowledgements}

The authors thank Idil Cakir for her editorial contribution.

\section{Author details}

${ }^{1}$ Intensive Care Unit, International Hospital, Istanbul Cad No: 82 Yesilkoy, 34149 Istanbul, Turkey. ${ }^{2}$ Intensive Care Unit, Ataşehir Memorial Hospital, Vedat Gunyol Cad. No:28 Kucukbakkalkoy Atasehir, 34758 Istanbul, Turkey.

Received: 28 November 2013 Accepted: 28 April 2014

Published: 6 June 2014

\section{References}

1. Wang $Y$, Teschler T, Weinreich G, Hess S, Wessendorf TE, Teschler H: Validation of microMESAM as screening device for sleep disordered breathing. Pneumologie 2003, 57:734-740.

2. Yaggi HK, Concato J, Kernan WN, Lichtman JH, Brass LM, Mohsenin V: Obstructive sleep apnea as a risk factor for stroke and death. N Eng $\mathrm{J}$ Med 2005, 19:2034-2041

3. Meoli AL, Casey KR, Clark RW, Coleman JA Jr, Fayle RW, Troell RJ, Iber C, Clinical Practice Review Committee: Hypopnea in sleep-disordered breathing in adults. Sleep 2001, 4:469-470.

4. Chen H, Lowe AA, Bai Y, Hamilton P, Fleetham JA, Almeida FR: Evaluation of a portable recording device (ApneaLink) for case selection of obstructive sleep apnea. Sleep Breath 2009, 3:213-219.

5. Baltzan MA, Verschelden P, Al-Jahdali H, Olha AE, Kimorf RJ: Accuracy of oximetry with thermistor (OxiFlow) for diagnosis of obstructive sleep apnea and hypopnea. Sleep 2000, 1:61-69.

6. Schwilk B, Muche R, Treiber H, Brinkmann A, Georgieff M, Bothner U: A cross-validated multifactorial index of perioperative risks in adults undergoing anaesthesia for non-cardiac surgery. Analysis of perioperative events in 26907 anaesthetic procedure. J Clint Monit Comput 1998, 4:283-294.

7. McAlister FA, Bertsch K, Man J, Bradley J, Jacka M: Incidence of and risk factors for pulmonary complications after nonthoracic surgery. Am J Respir Crit Care Med 2005, 5:514-517.

8. Leung JM, Dzankic S: Relative impotence of preoperative health status versus intraoperative factors in predicting postoperative adverse outcomes in geriatric surgical patients. J Am Geriatr Soc 2001, 8:1080-1085.

9. Scholes RL, Browning L, Sztendur EM, Denehy L: Duration of anaesthesia, type of surgery, respiratory co-morbidity, predicted $\mathrm{VO} 2 \mathrm{max}$ and smoking predict postoperative pulmonary complications after upper abdominal surgery: an observational study. Aust J Physiother 2009, 55:191-198.

10. Gibbs J, Cull W, Henderson W, Daley J, Hur K, Khuri SF: Preoperative serum albumin level as a predictor of operative mortality and morbidity: result from the National VA Surgical Risk Study. Arch Surg 1999, 1:36-42.

11. Mitchell CK, Smoger SH, Pfeifer MP, Vogel RL, Pandit MK, Donnelly PJ, Garrison RN, Rothschild MA: Multivariate analysis of factors associated with postoperative pulmonary complications following general elective surgery. Arch Surg 1998, 2:194-198.

12. Parker MJ, Handoll HH, Griffiths R: Anaesthesia for hip fracture surgery in adults. Cochrane Database Syts Rev 2004, 4, CD000521.

13. Kanat F, Golcuk A, Teke T, Golcuk M: Risk factors for postoperative pulmonary complications in upper abdominal surgery. ANZ J Surg 2007, 3:135-141.

14. Gupta RM, Parvizi J, Hanssen AD, Gay PC: Postoperative complications in patients with obstructive sleep apnea syndrome undergoing hip or knee replacement: a case-control study. Mayo Clin Proc 2001, 9:897-905.

15. Marin JM, Soriano JB, Carrizo SJ, Boldova A, Celli BR: Outcomes in patients with chronic obstructive pulmonary disease and obstructive sleep apnea: the overlap syndrome. Am J Respir Crit Care Med 2010, 3:325-331.

16. Chaouat A, Weitzenblum E, Kriger J, Ifoundza T, Oswald M, Kessler R: Association of chronic obstructive pulmonary disease and sleep apnea syndrome. Am J Respir Crit Care Med 1995, 1:82-86.

17. Young T, Peppard PE, Gottlieb DJ: Epidemiology of obstructive sleep apnea: a population health perspective. Am J Respir Crit Care Med 2002, 9:1217-1239.

18. Esteban A, Anzueto A, Alia I, Gordo F, Apezteduia C, Palizas F, Cide D, Goldwaser R, Soto L, Bugedo G, Rodrigo C, Pimentel J, Raimondi G, Tobin MJ: How is mechanical ventilation employed in the intensive care unit? An international utilization review. Am J Respir Crit Care Med 2000, 5:1450-1458.

19. Diehl JL, El Atrous S, Touchard D, Lemaire F, Brochard L: Changes in the work of breathing induced by tracheotomy in the ventilator-depended patients. Am J Respir Crit Care Med 1999, 2:383-388.

20. Hsu CL, Chen KY, Chang CH, Jerng JS, Yu CJ, Yang PC: Timing of tracheostomy as a determinant of weaning success in critically ill patients: a retrospective study. Crit Care 2005, 1:R46-R52.

21. Durbin CG Jr: Tracheostomy: why, when and how? Respir Care 2010, 8:1056-1068.

22. Christopher KL: Tracheostomy decannulation. Respir Care 2005, 4:538-5341.

23. Hernández G, Ortiz R, Pedrosa A, Cuena R, Vaquero Collado C, González Arenas P, García Plaza S, Canabal Berlanga A, Fernández R: The indication of tracheotomy conditions the predictors of time to decannulation in critical patients. Med Intensiva 2012, 8:531-539.

24. Spiriev T, Kondoff S, Schaller B: Trigeminocardiac reflex during temporary clipping in aneurismal surgery: first description. I Neurosurg Anesthesiol 2011, 3:271-272.

25. Spiriev T, Kondoff S, Schaller B: Cardiovascular changes after subarachnoid hemorrhage initiated by the trigeminocardiac reflex-first description of a case series. J Neurosurg Anesthesiol 2011, 4:379-380.

26. Nakagawa TA, Ashwal S, Mathur M, Mysore MR, Bruce D, Conway EE Jr, Duthie SE, Hamrick S, Harrison R, Kline AM, Lebovitz DJ, Madden MA, Montgomery VL, Perlman JM, Rollins N, Shemie SD, Vohra A, Williams-Phillips JA, Society of Critical Care Medicine, Section on Critical Care and Section on Neurology of the American Academy of Pediatrics, Child Neurology Society: Guidelines for determination of brain death in infants and children: an update of the 1987 Task Force recommendations. Crit Care Med 2011, 9:2139-2155.

27. Vardis R, Pollack MM: Increased apnea threshold in a pediatric patient with suspected brain death. Crit Care Med 1998, 11:1917-1917.

28. Wijdicks EF, Varelas PN, Gronseth GS, Greer DM, American Academy of Neurology: Evidence-based guideline update: determining brain death in 
adults: report of the Quality Standards Subcommittee of the American Academy of Neurology. Neurology 2010, 23:1911-1918.

29. Ma PL, Yang MS, Li Q, Qu H, Peng Y, Su JW, Zhao JZ: Study on safety of apnea test in clinical determination of brain death. Zhougguo Wei Zhong Bing Ji Jiu Yi Xue 2006, 5:260-263.

30. Goudreau JL, Wijdicks EF, Emery SF: Complications during apnea testing in the determination of brain death: predisposing factors. Neurology 2000, 7:1045-1048.

31. Scott JB, Gentile MA, Bennett SN, Couture M, Maclntyre NR: Apnea testing during brain death assessment: a review of clinical practice and published literature. Respir Care 2013, 3:532-538.

32. Lévesque S, Lessard MR, Nicole PC, Langevin S, LeBlanc F, Lauzier F, Brochu JG: Efficacy of a T-piece system and a continuous positive airway pressure system for apnea testing in the diagnosis of brain death. Crit Care Med 2006, 8:2213-2216

doi:10.1186/1752-1947-8-181

Cite this article as: Gücyetmez and Atalan: Apnea-hypopnea index use among intensive care patients: a case series. Journal of Medical Case

Reports 2014 8:181.

\section{Submit your next manuscript to BioMed Central and take full advantage of:}

- Convenient online submission

- Thorough peer review

- No space constraints or color figure charges

- Immediate publication on acceptance

- Inclusion in PubMed, CAS, Scopus and Google Scholar

- Research which is freely available for redistribution 